\title{
LAS ADICCIONES EN LOS AMBIENTES LABORALES: LA IMPERIOSA NECESIDAD DE RENOVACIÓN DEL ACTUAL ENFOQUE
}

\author{
ADDICTIONS IN LABOR ENVIRONMENTS: THE \\ IMPERIOUS NEED FOR RENEWAL OF THE CURRENT \\ APPROACH
}

\author{
Estefanía GONZÁLEZ COBALEDA ${ }^{1 *}$
}

Recibido: 01/09/2019

Aceptado: $11 / 02 / 2020$

\begin{abstract}
SUMARIO: I. Introducción: ¿de qué hablamos cuando nos referimos a adicciones? II. El carácter multicausal de los patrones adictivos y la magnitud de las adicciones en los ambientes de trabajo. III. El modelo de regulación y marco institucional: ¿existencia de una dispersión de planteamientos? IV. Hacia un nuevo enfoque: la gestión preventiva integral de seguridad y salud laboral. V. Propuestas de mejora y conclusiones. VI. Bibliografía.
\end{abstract}

SUMARY: I. Introduction: what do we talk to when we refer to addictions? II. The multicausal character of addictive patterns and the magnitude of addictions in work environments. III. The regulation model and institutional framework: is there a dispersion of approaches? IV. Towards a new approach: integral preventive management of occupational safety and health. V. Proposals for improvement and conclusions. VI. Bibliography.

RESUMEN: El tratamiento de las adicciones en los entornos laborales, hasta el momento, no tiene una adecuada respuesta en nuestro ordenamiento jurídico perpetuando un marco disciplinario y entrando en contradicción con el marco institucional que trata las adicciones y consumos problemáticos de drogas, sean legales o ilegales, desde la perspectiva de enfermedad. En este sentido, se debería de dar un paso más allá hacia el ámbito de la seguridad, salud y bienestar laboral. En efecto, pese a que las adicciones pueden ser ocasionadas por una multitud de factores o causas, donde sin duda alguna el componente individual o de la persona es muy relevante, además, es imprescindible atender también a los factores ambientales y del entorno, entre los que se encuentran los lugares de trabajo. De ahí que este estudio se centre en esa nueva perspectiva de tutela preventiva de los trabajadores, lo que supone la implicación de la empresa en un problema que le atañe, eliminando la visión acerca de que las adicciones como una cuestión extralaboral y únicamente asistencial.

PALABRAS CLAVES: consumos problemáticos, adicciones, drogas, riesgos psicosociales, prevención y sanción.

ABSTRACT: The treatment of addictions in the workplace, so far, does not have an adequate response in our legal system perpetuating a disciplinary framework and entering into contradiction with the institutional framework that deals with problematic

\footnotetext{
* Profesora en el área del Derecho del Trabajo y de la Seguridad Social en la Universidad de Jaén. https://orcid.org/0000-0002-5826-4012
} 
drug addictions and consumption, whether legal or illegal, from the perspective of disease. In this regard, a further step should be taken towards the field of occupational safety, health and welfare. Indeed, although addictions can be caused by a multitude of factors or causes, where without a doubt the individual component or the person is very relevant, in addition, it is also essential to attend to environmental and environmental factors, among Workplaces are found. Hence, this study focuses on this new perspective of preventive guardianship of workers, which implies the involvement of the company in a problem that concerns it, eliminating the view those addictions as an extra-labor issue and only care.

KEYWORDS: problematic consumption, addictions, drugs, psychosocial risks, prevention and sanction.

\section{INTRODUCCIÓN: ¿DE QUÉ HABLAMOS CUANDO NOS REFERIMOS A ADICCIONES?}

Las adicciones en términos amplios y los consumos problemáticos de drogas representan un grave y complejo panorama social, personal y laboral confirmado en la realidad. Este problema presenta diferentes intensidades incluso con relevante prevalencia en los ambientes laborales.

En cuanto a las características que definen dichos consumos podemos considerar necesario realizar una superflua distinción entre los diferentes conceptos relacionados con la materia, es decir, “consumo de drogas”, "consumos problemáticos” y "adicciones”, donde todas las organizaciones internacionales con competencias y solvencia plena (OMS, ONU, OIT) las distinguen.

En este sentido, según determina la OMS, cuando hablamos de "droga" hacemos referencia a toda sustancia que, introducida en el organismo, produce una alteración de algún modo del natural funcionamiento del sistema nervioso central del individuo, pudiendo ser en el pensamiento y/o conducta. Por tanto, podemos relacionarlo con drogas "legales” como son el alcohol, tabaco y fármacos, así como con las "ilegales”, es decir, sustancias psicotrópicas.

Asimismo, las "adicciones psicosociales de naturaleza conductuales o sin sustancia” es toda conducta compulsiva y repetitiva que no puede ser reprimida, es decir, crea dependencia aunque sea perjudicial para la persona que la presenta y para su entorno tanto familiar y social como laboral directo, además de alterar gravemente dichas relaciones. De manera que es la incapacidad de una persona de controlar dicha acción a pesar de intentarlo, además de mantenerlo pese a su nocividad ${ }^{2}$. Algunas adicciones psicosociales de naturaleza conductuales o sin sustancia pueden ser la ludopatía, abuso de las nuevas tecnologías digitales y/o redes sociales, la adicción al

\footnotetext{
${ }^{2}$ La Ley 1/2016, de atención integral de Adicciones y Drogodependencias, en su art. 7. b) define al trastorno adictivo como "toda conducta excesiva, que sin consumo de sustancias, se caracteriza por la tendencia irreprimible y continuada a su repetición, pese a ser perjudicial para la persona que la presenta y para su entorno (familiar, social y laboral) directo, por la incapacidad de controlarla a pesar de intentarlo y por su mantenimiento pese a su nocividad”.
} 
trabajo, exceso de consumo de comida calórica, adicción a las compras u oniomanía, entre otras ${ }^{3}$.

De hecho existen "consumos o usos responsables" siendo compatibles con la salud, si bien, los "consumos o usos de riesgo" se constatan como factores precursores de riesgo aunque no se actualiza todavía en daños graves.

Por otro lado, se encuentran los “consumos o usos problemáticos o nocivos” a corregir por ser inconciliable claramente con la salud psicosocial o bienestar y la estabilidad relacional.

Por último, los patrones de "consumos o usos adictivos" se conforman como una enfermedad psiquiátrica o trastorno de salud mental que implica limitaciones psicofísicas para una vida relacional en plenitud, con un fuerte sentimiento de compulsión para realizar la conducta y limitada capacidad para controlarla, alterando el ánimo cuando se limita o prohíbe la conducta, esto es, con síndrome de abstinencia y una relación conflictual con sus entornos por persistir en una conducta perjudicial.

Cualquier "adicción" es una enfermedad, independientemente que se encuentre o no catalogada como tal en la actualidad, según los manuales diagnósticos ${ }^{4}$. Con todo, lo que determina la aparición de riesgo de adicción no es el uso o consumo sino el tipo o patrón de consumo.

Por lo que se refiere al impacto derivado de los consumos problemático con o sin sustancias y adicciones, podemos determinar tres tipos de consecuencias.

El primer impacto, ciertamente, se produce sobre el propio sujeto que desarrolla dicha conducta que es el principal afectado por la misma a través de la pérdida de salud y bienestar -deudas, despido, etc.-.

La segunda consecuencia afecta sobre el conjunto de personas que forman parte de su círculo social y laboral, como puede ser a partir del deterioro de las relaciones, de exposición innecesaria a factores de riesgo presentes en el contexto laboral, de exposición a nuevos riesgos derivados del consumo, mediante la pérdida de apoyo social, estigmatización, entre otras.

Y, por último, la tercera consecuencia se produce sobre la propia organización empresarial en la que el trabajador desarrolla sus tareas a través de la pérdida de productividad, accidentalidad, deterioro de su reputación, deterioro del clima laboral, absentismo, elevados índices de rotación, etc.

De manera que las consecuencias no se reducen al propio trabajador que consume, sino que se extienden a su entorno de trabajo y al personal.

En definitiva, en las siguientes páginas se pretende realizar un estudio pormenorizado para comprender mejor la influencia que tienen los consumos problemáticos y adicciones en el lugar de trabajo. Para ello, se efectuará una aproximación de la realidad estadística con el propósito de profundizar en la constancia

\footnotetext{
${ }^{3}$ Para un mayor estudio sobre el tema Vid. MOLINA NAVARRETE, C., MIÑARRO YANINI, M., ÁlVAREZ MONTERO, A., GARCÍA CÍVICO, J. y GONZÁlEZ COBALEDA, E. "Drogodependencias y adicciones en los ambientes de trabajo: Buenas prácticas de regulación y gestión negociadas", Secretaría de Salud Laboral y Medio Ambiente UGT-CEC, 2016. Asimismo, Vid. MOLINA NAVARRETE, C. y VALLECILLO GÁMEZ, M.R.: Adicciones conductuales ("sin sustancia") "en" el trabajo y "al” trabajo: Magnitud del problema social y políticas de gestión preventiva en la empresa, Secretaría de Salud Laboral y Medio Ambiente UGT-CEC, 2018.

${ }^{4}$ Esta afirmación se sostiene en el Manual Diagnóstico y Estadístico de los Trastornos Mentales (DSM5). Dicho Manual se utiliza por médicos e investigadores internacionales en todas las áreas de la salud mental para diagnosticar y clasificar enfermedades mentales. En el mismo sentido, la OMS emplea la Clasificación Internacional de Enfermedades en su 10ª revisión (ICD-10-CM).
} 
o no de ellos en nuestro tejido productivo. Además, consideramos necesario estudiar la materialidad de los factores de riesgo y riesgos laborales en el mundo del trabajo con el objeto de identificar la verdadera necesidad que se ha de proteger y prevenir en las empresas.

A continuación, a partir de la relevancia de las nuevas tipologías de riesgos intangibles derivadas de las actuales condiciones contractuales y organización del trabajo, se realiza un especial énfasis en el análisis de los principales marcos, normativo e institucional, con la intención de tener un conocimiento preciso sobre la materia, trazando las principales líneas de acción que son necesarias implementar en la actualidad y basadas en la gestión preventiva integral en prevención de riesgos laborales.

En consecuencia, como podremos determinar, se trataría de llamar la atención sobre un ámbito crítico del modo de gestionar las adicciones en las organizaciones empresariales para someterlo a revisión desde una perspectiva psicosocial en materia de seguridad y salud laboral.

\section{EL CARÁCTER MULTICAUSAL DE LOS PATRONES ADICTIVOS Y LA MAGNITUD DE LAS ADICCIONES EN LOS AMBIENTES DE TRABAJO}

Los consumos problemáticos y las adicciones en términos generales constituyen un problema de suma relevancia en el ámbito laboral. Al respecto, ante la identificación de su importancia, la Delegación del Gobierno para el Plan Nacional sobre Drogas ha desarrollado la conocida Encuestas sobre Alcohol y Otras Drogas en España (EDADES) lo que permite observar la evolución de las prevalencias de consumo de drogas, legales e ilegales, los perfiles de los consumidores, la percepción de riesgo que tiene la población ante determinadas conductas de consumo, etc. Esta encuesta constituye un instrumento de investigación validado y consolidado, donde la muestra es altamente representativa, esto es, más de 21.249 sujetos respondieron al cuestionario de manera válida, con un error muestral máximo del $0,8 \%$, lo que le aporta una particular fiabilidad a los resultados obtenidos.

En este sentido, EDADES en su última edición del año $2017^{5}$ evidencia que el problema del consumo de drogas sigue siendo muy real. Ha confirmado que las drogas consumidas por un mayor porcentaje de personas son las legales. En primer lugar, el alcohol (75,2\%), en segundo lugar el tabaco (40,9\%). Continuando con la prevalencia de aquellas sustancias como son los hipnosedantes (con o sin receta) conformándose como la tercera sustancia más consumida $(11,1 \%)$, seguida por el cannabis $(11,0 \%)$. De manera más lejana nos encontramos con el consumo de cocaína (2,2\%), éxtasis $(0,6 \%)$ y anfetaminas (0,5\%).

En cuanto al sexo constituyen variables sociodemográficas muy relevantes en el patrón de consumo y en la prevalencia de unos consumos respecto de otros. Al respecto, los hipnosedantes y los analgésicos opioides son las únicas sustancias cuyo consumo está más extendido entre las mujeres (el 14,1\% frente a 8,1\% de hombres para hipnosedantes y 7,4\% frente a 5,9\% de hombres para analgésicos opioides). En el caso del cannabis el porcentaje de hombres que lo consume duplica ampliamente al de

\footnotetext{
${ }^{5}$ Para un estudio en profundidad acerca de la Encuesta sobre alcohol y otras drogas en España véase AA.VV. Encuesta sobre alcohol y otras drogas en España (EDADES), 1995-2017. Disponible en http://www.pnsd.mscbs.gob.es/profesionales/sistemasInformacion/sistemaInformacion/pdf/EDADES_20 17_Informe.pdf
} 
mujeres $(15,4 \%$ frente a $6,6 \%)$ y en el caso de la cocaína esta diferencia por sexo incluso llega a triplicarse (3,4\% hombres y 1,0\% mujeres).

También se dispone de datos relativos a la incidencia de las adicciones conductuales, es decir, como son el uso compulsivo de internet y la ludopatía. De tal forma que respecto al uso compulsivo de internet podemos concretar que un 2,9\% de la población de 15 a 64 años han hecho un uso compulsivo de internet. Igualmente, en relación al juego con dinero un $60,2 \%$ de la población con una edad comprendida entre los 15 a 64 años ha jugado en el último año ${ }^{6}$, donde los juegos más habituales son las loterías (94\%) seguidas de las loterías instantáneas (22,1\%) y las quinielas de futbol y/o quinigol $(16,4 \%)$.

Ante tales evidencias estadísticas nos podemos cuestionar la existencia o no de un único factor o causa que producen estos consumos problemáticos. En este sentido, debemos de determinar que no existe una única causa, sino que es una cuestión multifactorial y con un carácter interactivo entre ellas, obedeciendo a diferentes tipos de interacciones de la persona, sustancia y entorno. Por un lado, algunos estudios científicos ponen énfasis en los factores individuales como son acerca de la personalidad y genética, por otro lado, determinan que provienen de factores sociales, es decir, provenientes de los entornos, condicionantes sociales, etc. Sin embargo, a pesar de que sin duda alguna el componente o enfoque individual o de la persona es muy relevante, además, tanto el riesgo percibido por cada cual como la disponibilidad de sustancias influirá también en los consumos. Por lo tanto, es imprescindible atender además a los factores ambientales. De hecho, para comprender la problemática no podemos desvincular el entorno del trabajo y las adicciones, tal y como subraya la vigente Estrategia Nacional sobre Adicciones 2017-20247.

Para tener conciencia sobre la actual situación en los ambientes de trabajo hay que hacer referencia a la última Encuesta sobre consumo de sustancias psicoactivas en el ámbito laboral (en lo sucesivo, ECML) siendo la última disponible del período 2013$2014^{8}$. En ella se determina que la población laboral presentara "mayores prevalencias" en el consumo de ciertas drogas, aunque no de todas, respecto del conjunto de la población ${ }^{9}$. Si bien, atendiendo a la clasificación vista, resultan de interés comenzar especificando que, con carácter general, la puesta en relación de los consumos propios de la población laboral en relación con los propios de la población en general, no parece evidenciar diferencias estadísticamente significativas, si bien, pensamos que es trascendental analizar determinada información que nos propicia dicha encuesta.

\footnotetext{
${ }^{6}$ Para el análisis y estudio en profundidad de los datos, véase AA.VV. Informe sobre Adicciones comportamentales. Juego y uso compulsivo de internet en las encuestas de drogas y adicciones en $\begin{array}{lllll}\text { España EDADES } & y & \text { ESTUDES. } & \text { Disponible }\end{array}$ http://www.pnsd.mscbs.gob.es/profesionales/sistemasInformacion/sistemaInformacion/pdf/2019_Informe adicciones_comportamentales.pdf

${ }^{7}$ AA.VV. Estrategia Nacional sobre Adicciones. 2017-2024. Ministerio de Sanidad, Servicios Sociales e Igualdad, $2017 . \quad$ Disponible en http://www.pnsd.mscbs.gob.es/pnsd/estrategiaNacional/docs/180209_ESTRATEGIA_N.ADICCIONES_ 2017-2024_aprobada_CM.pdf

8 AA.VV. Encuesta 2013-2014 sobre consumo de sustancias psicoactivas en el ámbito laboral en España, Ministerio de Sanidad, Servicios Sociales e Igualdad, 2015. Disponible en http://www.pnsd.mscbs.gob.es/noticiasEventos/dossier/pdf/EncuestaLaboral2013.pdf

9 AA.VV. Encuesta 2013-2014 sobre consumo de sustancias psicoactivas en el ámbito laboral en España, óp. cit., pág. 46.
} 
Al respecto, todos los estudios disponibles, aunque sean muy escasos y dispersos, inciden en la misma dirección, las adicciones son siempre expresión de una multiplicidad de factores personales, sociales y/o ambientales, por lo que no se pueden imputar causalmente al trabajo, pero éste tiene gran relevancia, bien en su debut, bien en su agravación.

En concreto, la interacción puede representarse atendiendo a las condiciones o características de riesgo indicados de forma prevalente en la referida ECML ${ }^{10}$ y que resumimos en dos apartados, tal y como observamos en la siguiente tabla, como son los factores no laborales y factores laborales.

\section{TABLA 1. FACTORES DE RIESGO RELACIONADOS CON LOS CONSUMOS PROBLEMÁTICOS Y ADICCIONES EN TÉRMINOS GENERALES.}

\begin{tabular}{|c|c|}
\hline & FACTORES DE RIESGO \\
\hline \multirow{3}{*}{ NO LABORALES } & $\begin{array}{c}\text { SOCIALES } \\
\text { Tolerancia, disponibilidad, bajas garantías }\end{array}$ \\
\hline & $\begin{array}{c}\text { FAMILIARES } \\
\text { Conflictividad, malas relaciones de pareja, entre otras. }\end{array}$ \\
\hline & $\begin{array}{c}\text { PERSONALES } \\
\text { Baja autoestima, dificultad para resolver problemas y decidir, falta de } \\
\text { habilidades emocionales, insatisfacción, etc. }\end{array}$ \\
\hline \multirow{3}{*}{ LABORALES } & $\begin{array}{l}\text { ORGANIZACIÓN DEL TRABAJO } \\
\text { Jornadas prolongadas/pocos descansos, rotación horaria/trabajo } \\
\text { nocturno, ritmos de trabajo demasiado intensos, escasa posibilidad de } \\
\text { promoción profesional, descansos durante la jornada laboral, etc. }\end{array}$ \\
\hline & $\begin{array}{c}\text { PUESTO DE TRABAJO Y/O TAREAS } \\
\text { Trabajos repetitivos y monótonos, condiciones climatológicas adversas, } \\
\text { contaminación y toxicidad ambiental, trabajos aislados, traslados } \\
\text { frecuentes de puesto de trabajo, disponibilidad de sustancias, cultura del } \\
\text { puesto y/o profesión, etc. }\end{array}$ \\
\hline & $\begin{array}{c}\text { AMBIENTE LABORAL } \\
\text { Competitividad/Conflictividad laboral, inestabilidad laboral, } \\
\text { consumidores en el centro y tolerancia, accesibilidad general a ciertas } \\
\text { sustancias, entre otros. }\end{array}$ \\
\hline
\end{tabular}

FUENTE: MOLINA NAVARRETE, C.; et. alt.: La prevención del riesgo de adicciones en el medio laboral: obligaciones, recomendaciones y buenas prácticas. Claves para una Nota Técnica Preventiva del INSBT, óp. cit., pág. 18 y 20.

10 Vid. MOLINA NAVARRETE, C.; MIÑARRO YANINI, M.; ESCARABAJAR ARRIETS, M.D.; GIMENO NAVARRO, M.A. y GONZÁLEZ COBALEDA, E.: Condiciones de trabajo y riesgos psicosociales relacionados con las adicciones: Prevalencias de consumo y acciones preventivas en el entorno laboral, Secretaría de Salud Laboral y Medio Ambiente UGT-CEC, 2016, pág. 16. En el mismo sentido, vid. MOLINA NAVARRETE, et. alt.: La prevención del riesgo de adicciones en el medio laboral: obligaciones, recomendaciones y buenas prácticas. Claves para una Nota Técnica Preventiva del INSBT, Secretaría de Salud Laboral y Medio Ambiente UGT-CEC, 2018. Disponible en http://www.ugt.es/sites/default/files/ntp_adicciones_medio_laboral.pdf 
Cabe resaltar que el trabajo además de ser un "factor de riesgo" aumentando la probabilidad para ciertos niveles de consumos problemáticos, es igualmente un "factor de protección” frente a otros. De tal forma que estos factores de protección pueden ser situaciones, condiciones o elementos relacionados con el trabajo susceptible de disminuir la probabilidad de que se produzca el consumo problemático, el abuso de sustancias o las conductas excesivas con riesgo de generar adicciones. De ahí que podamos concretar dicha afirmación mediante la siguiente tabla.

\begin{tabular}{|c|c|c|}
\hline \multicolumn{3}{|c|}{$\begin{array}{l}\text { TABLA 2. FACTORES LABORALES RELACIONADOS CON LOS } \\
\text { CONSUMOS PROBLEMÁTICOS Y ADICCIONES A PARTIR DE LAS } \\
\text { CONDICIONES EN QUE SE PRESTA EL TRABAJO. }\end{array}$} \\
\hline $\begin{array}{c}\text { FACTORES } \\
\text { LABORALES }\end{array}$ & FACTORES DE RIESGO & FACTORES DE PROTECCIÓN \\
\hline $\begin{array}{l}\text { Condiciones de } \\
\text { empleo }\end{array}$ & $\begin{array}{ll}\checkmark & \text { Inseguridad en el empleo } \\
\checkmark & \text { Trabajo externalizado (redes) }\end{array}$ & $\begin{array}{l}\checkmark \quad \text { Condiciones de seguridad o } \\
\text { garantía de empleo }\end{array}$ \\
\hline $\begin{array}{l}\text { Condiciones } \\
\text { contractuales } \\
\text { (jornada y } \\
\text { retribución) }\end{array}$ & $\begin{array}{ll}\checkmark & \text { Jornadas prolongadas } \\
\checkmark & \text { Incertidumbre sobre descansos } \\
\checkmark & \text { Devaluación de condiciones } \\
\checkmark & \text { Baja expectativa de desarrollo } \\
& \text { de carrera profesional }\end{array}$ & $\begin{array}{ll}\checkmark & \text { Condiciones de conciliación de } \\
\checkmark & \text { la vida laboral y familiar } \\
\checkmark & \text { Carrera profesional } \\
\checkmark & \text { Mejoras de acción social }\end{array}$ \\
\hline Factores Ambientales & $\begin{array}{ll}\checkmark & \text { Factores ambientales } \\
\checkmark & \text { Continuidad de trabajo tóxicos } \\
\checkmark & \text { Climatología adversa }\end{array}$ & $\begin{array}{ll}\checkmark & \text { Compromisos de eliminación } \\
& \text { de puestos tóxicos o peligrosos } \\
\checkmark & \text { Evaluaciones ergonómicas }\end{array}$ \\
\hline $\begin{array}{c}\text { Factores } \\
\text { Psicosociales }\end{array}$ & $\begin{array}{ll}\checkmark & \text { Elevada carga de trabajo } \\
\checkmark & \text { Ritmo intensivos } \\
\checkmark & \text { Nocturnidad/aislamiento } \\
\checkmark & \text { Insatisfacción relacional } \\
\checkmark & \text { Competitividad/Conflictividad }\end{array}$ & $\begin{array}{ll}\checkmark & \text { Evaluación de factores de } \\
\text { riesgos psicosociales } \\
\checkmark \quad \text { Calidad de clima relacional }\end{array}$ \\
\hline
\end{tabular}

FUENTE: MOLINA NAVARRETE, C.; et. alt.: La prevención del riesgo de adicciones en el medio laboral: obligaciones, recomendaciones y buenas prácticas. Claves para una Nota Técnica Preventiva del INSBT, óp. cit., pág. 21.

Ante la relevancia del problema no sorprende que ECML determine que casi el 53\% de la población laboral encuestada considera "muy importante" el problema relativo al consumo de drogas en los centros de trabajo, incluso, casi nueve de cada diez trabajadores opinan que es un problema importante. Los motivos por los que inquieta el problema principalmente son porque provocan accidentes laborales $(60,8 \%)$, disminuye la productividad (51,3\%), genera un mal ambiente o entono de trabajo (42,2\%); incrementa el absentismo laboral (37,1\%), entre otros.

Incluso podemos analizar y estudiar la relación en función del sector de actividad donde se constatan más evidencias relevantes de relación, sino directa, sí indirecta, entre el trabajo y el consumo de drogas. 


\begin{tabular}{|c|c|c|c|c|c|}
\hline \multicolumn{6}{|c|}{$\begin{array}{l}\text { TABLA 3. PORCENTAJE DE POBLACIÓN LABORAL QUE HA } \\
\text { CONSUMIDO DIFERENTES SUSTANCIAS POR SECTOR DE ACTIVIDAD, } \\
\text { AÑO } 2014 .\end{array}$} \\
\hline & Alcohol & Tabaco & Hipnosedantes & Cannabis & Cocaína \\
\hline Construcción & 19,4 & 43,4 & 4,8 & 11,7 & 3,9 \\
\hline Hostelería & 11,3 & 42,6 & 8,2 & 10,9 & 4 \\
\hline $\begin{array}{c}\text { Agricultura, pesca, } \\
\text { ganadería y extracción }\end{array}$ & 13,5 & 40,2 & 4,1 & 7,2 & 2 \\
\hline $\begin{array}{l}\text { Actividades artísticas, } \\
\text { recreativas y deportivas }\end{array}$ & 7,3 & 34,1 & 6,5 & 10,4 & 5,6 \\
\hline $\begin{array}{c}\text { Industria manufacturera y } \\
\text { suministros }\end{array}$ & 11,6 & 36 & 6,6 & 6,2 & 2,4 \\
\hline $\begin{array}{c}\text { Transporte, } \\
\text { almacenamiento y } \\
\text { comunicaciones }\end{array}$ & 11,1 & 32,3 & 5 & 6,9 & 2,3 \\
\hline $\begin{array}{c}\text { Comercio y reparación } \\
\text { vehículos a motor }\end{array}$ & 8,7 & 33,5 & 6,2 & 6,6 & 2 \\
\hline $\begin{array}{l}\text { Act. financiera, seguros, } \\
\text { inmobiliarias y serv. } \\
\text { empresariales }\end{array}$ & 10,5 & 30 & 7,8 & 5 & 2,3 \\
\hline $\begin{array}{l}\text { Actividades domésticas y } \\
\text { servicios personales }\end{array}$ & 4 & 28,8 & 10,9 & 4,3 & 1,2 \\
\hline $\begin{array}{c}\text { Admón. pública, } \\
\text { educación, sanidad y serv. } \\
\text { sociales }\end{array}$ & 8,4 & 25,8 & 8,6 & 3,6 & 1,3 \\
\hline MEDIA & 10,5 & 33,8 & 7,3 & 6,7 & 2,4 \\
\hline
\end{tabular}

En este sentido, observamos como el sector de la hostelería es la actividad económica que mayores consumos problemáticos se dan entorno a todas las sustancias, es decir, en cuanto al alcohol, tabaco, hipnosedantes, cannabis y cocaína. En consecuencia, consideramos que en dicho sector de actividad se han de desarrollar de manera urgente políticas más eficaces de gestión del riesgo de consumos problemáticos.

Igualmente, llama la atención que la actividad donde más prevalencia de consumo de alcohol a diario, es decir, entre los que se incluyen los días laborables, si es cierto que desconocemos si es dentro o próximo a la jornada laboral, es en el sector de la construcción. A este aspecto, hay que mencionar que este sector de actividad es caracterizado por su especial peligrosidad, esto es, alcanza el mayor índice de incidencia de accidentes de trabajo ${ }^{11}$, por tanto, el elevado consumo de alcohol que se produce

\footnotetext{
${ }^{11}$ El sector de la construcción alcanzó en el año 2019 la incidencia más alta de los accidentes en jornada con baja. Este índice de incidencia se presenta como uno de los más elevados desde el año 2007. Vid. Disponible en http://www.mitramiss.gob.es/estadisticas/eat/eat19/Resumen_resultados_ATR_2019.pdf
} 
entre estos trabajadores incrementa la peligrosidad de una actividad que objetivamente ya lo es, al añadir un importante factor de riesgo subjetivo.

En contraste con todo lo anterior nos lo encontramos con el consumo de hipnosedantes. Los patrones de elevados consumos aparecen principalmente en el sector de actividades domésticas y servicios personales. El segundo puesto de prevalencias en relación al consumo de hipnosedantes es para el sector de empleo público en el cual constatamos un incremento de consumos en el sector educativo, el sanitario y el de servicios sociales (8,6 \%). El tercero lo ocupa la hostelería (8,2 \%).

En particular, debemos de tener presente que en los sectores de empleo público las actividades se caracterizan por un trabajo con una mayor carga emocional, pudiendo constatarse como un factor de riesgo, además, siendo sectores con una alta feminización. En estas actividades se produce un elevado nivel de responsabilidad y de las exigencias de demanda, caracterizándose por quedar supeditado el bienestar propio al ajeno, lo que provoca una elevada carga psicosocial de trabajo. Asimismo, se trata además de actividades en las que son frecuentes la violencia y los conflictos relacionales con clientes, pacientes, alumnos, etc., esto es, favorece alteraciones emocionales, derivando en estrés y ansiedad.

Por todo lo anterior que cabe deducir una correlación entre el porcentaje de personas consumidores de las diferentes drogas, sean legales o ilegales, y la exposición a ciertas condiciones de trabajo. En particular, entre los factores que se encuentran con mayores prevalencia y en todos los consumidores, son los relacionados con los estilos de gestión o de dirección empresarial, es decir, "insatisfecho/a con el trato de los superiores"; con unas "jornadas con escaso tiempo de descanso" y con un "trabajo que exige rendimiento muy alto". 


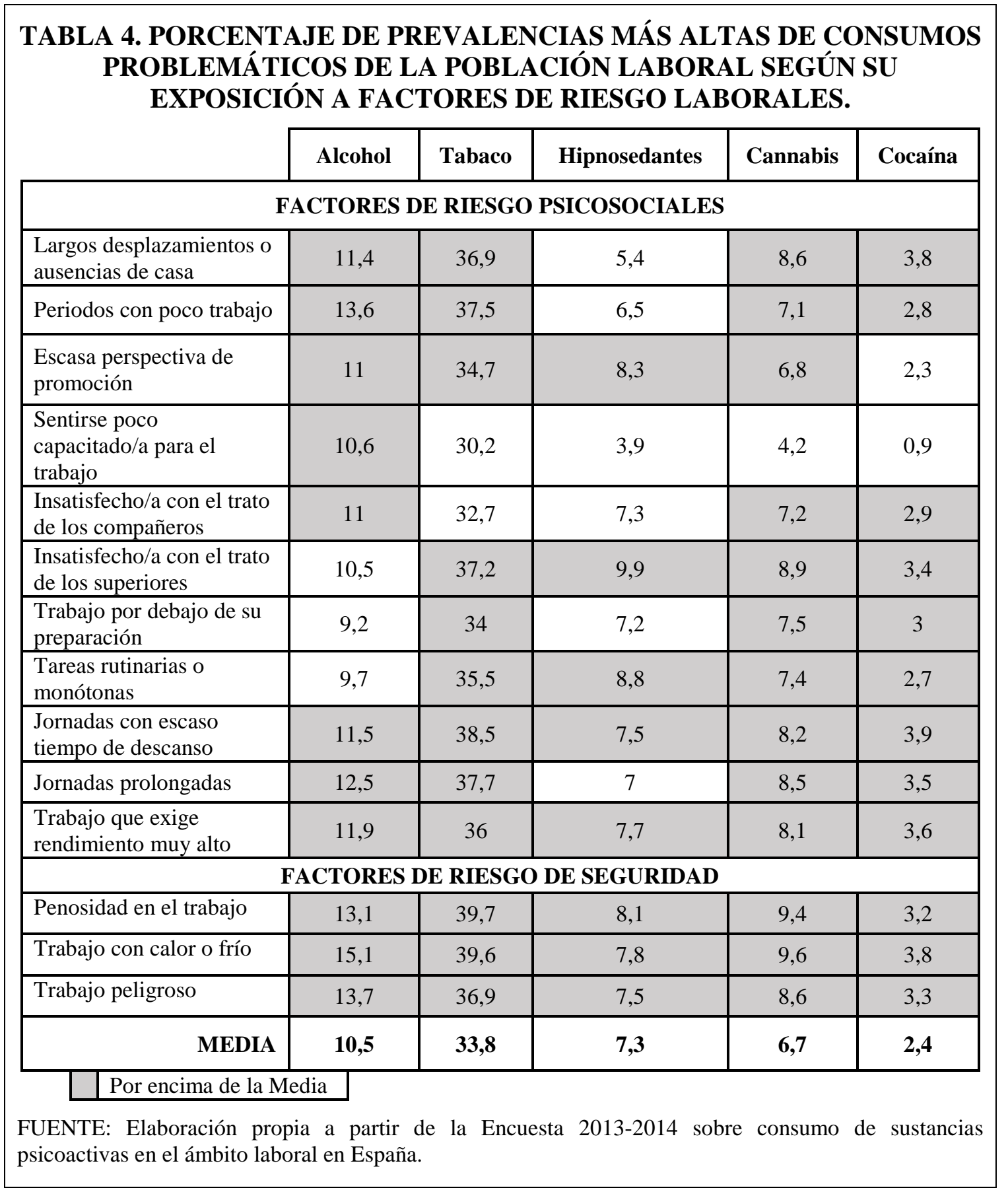

Cabe deducir una correlación entre el porcentaje de personas consumidores de drogas, sean legales o ilegales, y la exposición a ciertos riesgos laborales, si es cierto que no son sólo los referidos factores psicosociales de riesgo, no obstante, sí son los más frecuentes.

De manera que, como hemos podido comprobar a partir de los anteriores datos, no podemos cuestionar que las adicciones sea una cuestión únicamente a decisiones individuales y a factores socio-culturales y externos a la empresa, sino que además habría que añadir la influencia de factores socio-económicos y laborales en las derivas de patrones adictivos. 
Al respecto, es importante la prevención y el tratamiento adecuado de los consumos problemáticos y las adicciones en general por parte de las organizaciones empresariales, donde dicha problemática impacta de manera negativa no solo en el propio consumidor y su entorno, sino también a la empresa, multiplicando el riesgo de siniestralidad laboral, desciendo la productividad, deteriorando el clima laboral, la calidad del trabajo, etc. En concreto, se han de producir una implicación para el abordaje de tales situaciones basándose en la prevención en materia de seguridad y salud laboral. No obstante, como analizaremos a continuación, no es la línea de acción que con carácter general se desarrolla. El enfoque actual se basa en el tratamiento individualista, represivo y sancionador, siendo distante de la gestión preventiva que aquí defendemos.

\section{EL MODELO DE REGULACIÓN Y MARCO INSTITUCIONAL: ¿EXISTENCIA DE UNA DISPERSIÓN DE PLANTEAMIENTOS?}

Tradicionalmente en las organizaciones empresariales se ha proyectado las adicciones y los consumos problemáticos de drogas desde la perspectiva sancionadora contenida en el art. 54.2 f) Estatuto de los Trabajadores $(E T)^{12}$, siendo la única referencia específica contenida en la normativa general. En este precepto se recoge el incumplimiento grave y culpable por parte del trabajador por la "embriaguez habitual o toxicomanía si repercuten negativamente en el trabajo" legitimándose la sanción máxima como es el despido disciplinario.

Desde esta perspectiva, una primera cuestión relevante a efectos de analizar la adecuación o no de la configuración sancionadora, consiste en determinar si el propio art. 54.2 f) ET puede generar conflictos con respecto a distintos derechos constitucionales relativos a la salud del trabajador. Así, debemos de tener presente el “derecho a la vida y a la integridad física y moral” (art. 15 de la CE), el derecho a "la seguridad e higiene en el trabajo" (art. 40.2 de la CE), el "derecho a la protección de la salud" (art. 43 de la CE) y al derecho a "disfrutar de un medio ambiente adecuado" (art. 45 de la $\mathrm{CE}$ ) reconocidos al trabajador, siendo indispensable que se traten de forma conjunta ${ }^{13}$.

Precisamente, la CE garantiza el deber genérico del derecho a la protección de la salud referida a todos los ciudadanos, estableciendo un vínculo entre el derecho a la salud y el derecho al trabajo ${ }^{14}$, donde este último no comporte un peligro a partir de las propias condiciones de trabajo, respetando la vida e integridad física, mental y social de la persona ${ }^{15}$ de manera constante y progresiva en materia del bienestar general ${ }^{16}$ para el

\footnotetext{
12 Vid. MOLINA NAVARRETE, C.; et. al.: Condiciones de trabajo y riesgos psicosociales relacionados con las adicciones: Prevalencias de consumo y acciones preventivas en el entorno laboral, óp. cit., pág. 28. Igualmente, Vid. MOLINA NAVARRETE, C. et. al.: Drogodependencias y adicciones en los ambientes de trabajo: Buenas prácticas de regulación y gestión negociadas, óp. cit., pág.29.

13 Vid. GÓMEZ SALADO, M.A.: "El absentismo laboral como causa del despido objetivo. Puntos críticos en la redacción del artículo 52 d) del Estatuto de los Trabajadores”, Editorial Comares, Granada, 2019, pág.64.

${ }^{14}$ Vid. RODRÍGUEZ-PIÑERO Y BRAVO-FERRER, M.: "La integración de los derechos fundamentales en el contrato de trabajo”, en AA.VV. MARTÍN JIMÉNEZ, R. y SEMPERE NAVARRO, A.V. (coord.) El modelo social en la Constitución española de 1978, 2003, pág. 214.

${ }^{15}$ Vid. GONZÁLEZ-POSADAS MARTÍNEZ, E.: “La seguridad y salud de los trabajadores”, en AA.VV. SEMPERRE NAVARRO, A.V. (Dir.) El modelo social en la Constitución Española de 1978, Ministerio de Trabajo y Asuntos Sociales, Madrid, 2003, pág. 761.
} 
individuo como condición de ser humano ${ }^{17} \mathrm{y}$, por tanto, también a los ciudadanostrabajadores ${ }^{18}$.

A este respecto, se debe de considerar que la embriaguez y toxicomanía no son "enfermedades voluntarias", sino que, a pesar de que la casuística puede ser variada, la conducta adictiva excluye la voluntariedad por la dependencia a la sustancia o conducta adictiva. De hecho, no podemos obviar, como mencionábamos, que las conductas adictivas no tienen que ser directamente derivadas causalmente al trabajo, pero éste tiene gran relevancia, bien en su debut, bien en su agravación. En este sentido, la regulación legal del despido disciplinario por el incumplimiento grave y culpable por parte del trabajador supone un claro desequilibrio jurídico en favor a los intereses del empleador y en detrimento de los intereses del trabajador, poniendo en tela de juicio algunos derechos constitucionales.

Lo cierto es que a nuestro entender consideramos que este modelo de regulación represivo es un enfoque obsoleto ${ }^{19}$. Entendemos que la organización empresarial que únicamente implementa la vía sancionadora trata de silenciar el problema expulsando al trabajador afectado, incluso, como consecuencia el trabajador consumidor de riesgo y sus compañeros ocultará dichas adicciones y consumos para evitar sanciones ${ }^{20}$, por lo cual la "ley del silencio" es erróneamente cómplice de dichos entornos de trabajo en los que se establecen factores de riesgo que potencian las conductas adictivas. De manera que seguimos anclados, por lo que al ámbito jurídicolaboral se refiere, en la lógica represivo-disciplinaria, siendo impropia para un ordenamiento jurídico moderno ${ }^{21}$ y ajena a los principios preventivos y de tutela de la salud que presiden nuestros sistemas de seguridad y salud en el trabajo y sanitario ${ }^{22}$.

\footnotetext{
${ }^{16}$ Vid. GONZÁLEZ ORTEGA, S.: “La seguridad e higiene en el trabajo en la Constitución, en Revista de Política Social, núm. 121, 1979, pág. 220. Asimismo, relaciona dicho derecho fundamental con la tesis defendida acerca de su eficacia a cualesquiera ámbitos de actuación del ser humano PALOMEQUE LÓPEZ, M.C.: “El derecho constitucional del trabajador a la seguridad en el trabajo", en Actualidad Laboral, II, 1992, pág. 39. En el mismo sentido, por el mismo autor, "La protección del trabajador frente a los riesgos laborales”, en DS: Derecho y salud, Vol. 4, núm. 1, 1996, pág. 27. Igualmente, GARRIGUES GIMÉNEZ, A.: "La prevención de riesgos laborales en el marco de la Constitución Europea”, en Revista del Ministerio de Trabajo y Asuntos Sociales, núm.57, 2005, pág. 366.

17 Vid. GARRIDO FALLA, F.: “Artículo 43”, en AA.VV.: GARRIDO FALLA, F. (coord.): Comentarios a la Constitución, Civitas, Madrid, 1985, pág.501.

${ }^{18}$ Con respecto a esta cuestión, se ha determinado que la celebración de un contrato de trabajo no implica en modo alguno la privación para una de las partes, el trabajador, de los derechos que la Constitución Española le reconoce como ciudadano, véase STC 88/1985, de 19 de julio. Asimismo, la STC de 12 de septiembre de 2005, Rec. 1221/2002.

19 Se ha generado dispares posicionamientos jurídicos acerca del art. 54.2 f) ET ocasionando una inseguridad aplicativa. De modo que cuando se utiliza trata de respaldar otros incumplimientos contractuales, por tanto, entendemos que este precepto es disfuncional e innecesario, careciendo de utilidad, puesto que existen otros preceptos sancionadores más garantistas con idéntico resultado. En este sentido, en la STSJ de Valladolid, de 12 de julio de 2019 (rec. núm. 1053/2019) falla que la conducción del camión por el actor bajo los efectos de las sustancias prohibidas implica, además de una falta muy grave por embriaguez habitual o toxicomanía si repercuten negativamente en el trabajo, el quebranto de la buena fe contractual y una deslealtad en las funciones encomendadas. En el mismo sentido, la STSJ de Cataluña de 21 de marzo de 2016 (Rec. núm. 1850/2016).

${ }^{20}$ Vid. MIÑARRO YANINI, M.: "El modelo regulador de las adicciones en los ambientes de trabajo en España: Contradicciones y propuestas de cambio”, en Temas Laborales, núm. 134, 2016, págs. 108.

${ }^{21}$ Es interesante la evolución de la doctrina entorno al consumo ocasional y la supresión del tratamiento represivo, véase la STSJ de Les Illes Balears, Sala de lo Social, de 22 marzo 2019 (Rec. núm. 532/2018), donde se declara improcedente el despido de conductor de autobús que tras un grave accidente de tráfico en el que muere un motociclista, da positivo en el test de drogas. Se determina que, a diferencia de lo que
} 
Frente a esta dimensión sancionadora, lentamente y de manera progresiva, se implementa un marco de gestión integral promoviendo primordialmente una acción de prevención, así como una acción médico-asistencial, si bien, cuando la primera medida falla. Así, con este enfoque las intervenciones preventivas tienen como objetivo reducir los factores de riesgo e incrementar los factores de protección frente a toda conducta susceptible de generar adicción, conformándose una perspectiva renovada e innovadora, encontrando fundamentos legales para reconducir la gestión del riesgo de consumos nocivos de drogas y otras adicciones en el trabajo a través de la Ley 31/1995, de 8 de noviembre, de prevención de riesgos laborales (LPRL).

Si bien, a pesar de que no existe una regulación específica en la norma del sistema normativo de seguridad y salud en el trabajo que atienda la cuestión del alcoholismo, las drogodependencias $\mathrm{y}$, aún menos, las adicciones en general, no significa que tal ausencia sea exclusión alguna del sistema normativo preventivo necesariamente ${ }^{23}$. Para ello, es necesaria la comprensión integral en esta materia sobre la conceptualización de las adiciones a partir del concepto de seguridad y salud acogido por la LPRL, y, en una estricta conexión con él, a los principios de la acción preventiva bajo tres principios.

En virtud de todo lo anterior, estos principios son, en primer lugar, el principio ergonómico [art. 15.1 letra d) LPRL] de adaptar el trabajo a la persona con miras a reducir los efectos del mismo en la salud, pues como se ha puesto de relieve supra, algunas condiciones de trabajo tienen una mayor prevalencia en las adicciones y, por tanto, tienen incidencia en su pérdida de salud. Como consecuencia de ello, a nuestro juicio, es determinante y clara la subjetividad que se establece en el precepto, donde si el trabajo lo prestara otro trabajador que no fuera vulnerable o con sensibilidad, no

ocurre con el alcohol, el simple hecho de dar positivo no prueba que se condujera bajo los efectos del cannabis, cuyos efectos se esfuman en un máximo de 48 horas, pero que dejan rastro en la sangre hasta diez días después del consumo. De hecho, como ni el compañero de trabajo ni los agentes policiales detectaron un comportamiento extraño en el actor, podría haberla tomado en su tiempo libre, máxime cuando el día anterior fue de libranza. En el mismo sentido, STSJ de Madrid, Sala de lo Social, 928/2016, de 2 de noviembre. 2016.

${ }^{22}$ Es interesante concretar una propuesta que a pesar de que no prosperó evidenció la necesidad de un cambio del enfoque actual por no ser adecuadas las vías de tratamiento en orden a la recuperación de las adicciones. En este sentido, el 2 de octubre de 2000 (Boletín Oficial de las Cortes Generales -Congreso de los Diputados- de 6 de octubre de 2000) el Grupo Parlamentario Popular, estando en el Gobierno, presentó en el Congreso una Proposición de Ley cuyo único artículo disponía "se suprime la letra f) del apartado 2 del artículo 54 del texto refundido de la Ley del Estatuto de los Trabajadores, aprobado por Real Decreto Legislativo 1/1995, de 24 de marzo". Determinaban que era innecesario y disfuncional este modelo sancionador de patrones de conducta socio-personal y sólo por los impactos negativos en la actividad laboral, por lo tanto, careciendo de utilidad, puesto que existen otros preceptos sancionadores suficientes y más garantistas con idéntico resultado, incluso siendo contraproducente a efectos de rehabilitación y reinserción de estas enfermedades.

${ }^{23}$ Del mismo modo que la ausencia de referencia al conjunto de los riesgos psicosociales relacionados con el trabajo, hasta hace poco tiempo considerado como un elemento justificativo de su escaso desarrollo en las evaluaciones de riesgo, no justificaría su exclusión, como recientemente confirma la jurisprudencia. En este sentido, a título de ejemplo véase la STS, 4a 16 de febrero de 2016, Rec. 250/2014. 
supondría específicas medidas de protección ${ }^{24}$. Por tanto, la especial sensibilidad se halla en el propio trabajador e inherentes al individuo ${ }^{25}$.

En segundo lugar, el principio de salubridad integral [art. 1.5.1 letra g) LPRL], donde la prevención ha de buscar un conjunto coherente que integre en ella la técnica, la organización del trabajo, las condiciones de trabajo, las relaciones sociales y la influencia de los factores ambientales en el trabajo, conformándose, a nuestro juicio, como un precepto crucial para un enfoque preventivo del consumo nocivo de drogas y adicciones en los entornos laborales. En efecto, este precepto, además de resaltar el aspecto central del deber empresarial y de la seguridad y salud en el trabajo, contiene el valor añadido de reforzar el alcance de dicho deber mediante los factores de riesgo a considerar. En este sentido, se deberán de abarcar todos los riesgos laborales posibles, por tanto, más allá de los tradicionales, además, se deberá de atender a los "factores de riesgo" tanto internos como externos a la actividad y prestación de servicios ${ }^{26}$ que puedan afectar negativamente a la seguridad y salud e incluso al bienestar ${ }^{27}$ (arts. 4.2, 4.3, 4.7 y 14.2 LPRL).

Por último, el principio referente a primar la protección colectiva, es decir, al conjunto de la plantilla de trabajadores frente a la protección individual o de la persona [art. 15.1.h) LPRL]. Esta perspectiva subyace de la percepción de que la protección colectiva es más eficaz debido a que neutraliza los riesgos en su origen o puede reducir el riesgo con carácter general ${ }^{28}$.

En cualquier caso, este renovado enfoque de gestión de la seguridad y salud en el trabajo, integradora de la prevención propiamente dicha, asume dos cambios fundamentales. Por un lado, el tránsito desde el "tratamiento" de las personas consumidoras de riesgo a la prevención del consumo, evitando que los trabajadores

\footnotetext{
${ }^{24}$ Vid. GARCÍA NINET, J.I., y VICENTE PALACIO, A.: "Artículo 25. Protección de trabajadores especialmente sensibles a determinados riesgos”, en AA.VV. MONEREO PÉREZ, J.L., MOLINA NAVARRETE, C. y MORENO VIDA, M.N. (dirs.) Comentario a la Ley de Prevención de Riesgos Laborales y sus desarrollos reglamentarios, Comares, Granada, 2004, pág. 251.

${ }^{25}$ Vid. GARCÍA-PERROTE ESCARTÍN, I.: "Protección de trabajadores especialmente sensibles a determinados riesgos", en AA.VV. CASAS BAAMONDE M.E., PALOMEQUE LÓPEZ M.C., VALDÉS DAL-RE, F (coord.), Seguridad y Salud en el Trabajo. El nuevo derecho de prevención de riesgos profesionales. La Ley-Actualidad, Madrid, 1997, pág. 37.

${ }^{26}$ En este sentido, no podemos obviar una reciente sentencia, STSJ de Cantabria, núm. 226/2019, de 20 de marzo de 2019, dispone que los riesgos psicosociales han de formar parte de la política preventiva de la empresa y, si por cualquier cuestión no lo desarrollara, esta incumpliría en relación a sus obligaciones, por lo tanto, ha de afrontar una indemnización aunque no se hayan constatado daños a la salud. En el mismo sentido, STS 544/2018, Sala de lo Social, de 17 de mayo de 2018 (rec. núm. 3598/2016). Además, STS de 17 de junio de 2008 y el CT 87/2011, sobre actuaciones Inspectoras en relación al riesgo laboral de atraco y la Orden Ministerial, ESS/1651/2013, de 29 de julio, en materia de prevención de las lesiones causadas por instrumentos cortantes y punzantes en el sector hospitalario y sanitario, pues determinan que se han de atender a los factores de riesgo para establecerse el carácter integral e integrado de la gestión preventiva de todos los riesgos laborales, independientemente del tipo de riesgo laboral que se trate. Asimismo, Vid. MOLINA NAVARRETE, C.: "La tutela frente a la $<<$ violencia moral $>>$ en los lugares de trabajo: entre prevención e indemnización”, Aranzadi Social, núm. 18, 2002, págs. 67 y 68.

${ }^{27}$ Vid. MONEREO PÉREZ, J.L. y MOLINA NAVARRETE, C.: "Capítulo 1: La caracterización general de la prevención de los riesgos laborales: Conceptos y fundamentos jurídicos-críticos del nuevo modelo de acción preventiva”, en AA.VV. MONEREO PÉREZ, J.L. y MOLINA NAVARRETE, C. (dir.): Tratado de Prevención de Riesgos Laborales. Teoría y Práctica, Tecnos, Madrid, 2015, pág. 20.

${ }^{28}$ Vid. RIVERO LAMAS, J. Y DE VAL TENA, A. L.: "Artículo 15. Principios de la acción preventiva”, en AA.VV. MONEREO PÉREZ, J.L.; MOLINA NAVARRETE, C. y MORENO VIDA, M.N. (drs.): Comentario a la Ley de Prevención de Riesgos Laborales y sus desarrollos Reglamentarios, Comares, Granada, 2004, págs. 137 y 138.
} 
saludables enfermen. Por otro, la protección debe dirigirse al conjunto de la población trabajadora -la plantilla entera para cada empresa- (acción universal), y no sólo centrarse en la atención a la persona o grupos problemáticos (acción selectiva o de cribado).

La OIT desde hace años a través del PROGRAMA SOLVE ${ }^{29}$ viene proponiendo que es más eficaz, en el plano social, a la vez más eficiente económicamente, integrar la promoción de la salud en el trabajo a través del fomento de hábitos adecuados de vida en los sistemas de gestión preventiva de riesgos laborales ${ }^{30}$. Trata de facilitar ese doble cambio tanto conceptual como práctico aportando una estudio en profundidad de cómo implementar una plena integración de la "promoción de la salud”, ámbito propio de la gestión de los usos nocivos de drogas, en las más específicas "políticas de seguridad y salud en el trabajo" de las empresas, a fin de que asuman una dimensión integral, coherente con el concepto de salud que les sirve de referencia ${ }^{31}$. De modo que para la OIT las políticas de seguridad y salud en el trabajo no sólo deben dirigirse a la prevención de los accidentes y enfermedades asociados directamente al trabajo, sino que han de contribuir a la mejora de la salud y el bienestar generales de la población.

Plenamente consciente de todo este cúmulo de evidencias científicas y de posiciones institucionales, tanto las diferentes Estrategias Española sobre Drogas y sus Planes de Acción, ya extintos, como la actual Estrategia Española de Adicciones (2017$2024)^{32}$ y su Plan de acción sobre adicciones $(2018-2020)^{33}$, han asumido la necesidad de aprovechar esa conexión, de promover las sinergias entre la promoción de la salud frente a hábitos de riesgo adictivo y la protección de la seguridad y salud en el trabajo. Uno de los elementos más novedosos de la nueva Estrategia es su carácter "global", pues no sólo amplía el foco tradicionalmente puesto en las drogas a otros aspectos, como son las nuevas formas de adicción y patrones de consumo por el aumento del uso "patológico" de Internet, los medios digitales y las redes sociales. Igualmente, esta Estrategia incide más en los factores ambientales que en los individuales o de la persona. Consecuentemente, junto a otros ámbitos organizativos sociales, como la escuela o la familia, reclama la atención sobre el ambiente de trabajo, a través de la prevención de las conductas de riesgo y la promoción de conductas saludables. Si bien, como es sabido, estas previsiones no son de carácter obligatorio, quedando confiada a

\footnotetext{
29 Vid. AA.VV. SOLVE: Integrando la promoción de la salud a las políticas de SST en el lugar de trabajo, OIT, 2012. Disponible en https:/www.ilo.org/safework/info/instr/WCMS_203117/lang-es/index.htm

30 Es llamativo que las políticas y recomendaciones prácticas de la OIT acerca de esta materia se remontan al año 1996, incluso, que se incluya también adicciones sin sustancia, esto es, conductuales (juego, nuevas tecnologías, etc.), donde su estudio de referencia principal sigue siendo el "Repertorio de recomendaciones prácticas relacionadas con la incidencia del alcohol y las drogas en los lugares de trabajo". En este sentido, en Convenio de la OIT 187, relativo a un "marco promocional de la seguridad y salud en el trabajo", llamaba a una renovación significativa de la "política de prevención de riesgos laborales", mediante el impulso de "políticas de promoción de la salud en el trabajo". Esto es, ambientes de trabajo no sólo "seguros" y "sanos", sino también "saludables".

${ }^{31}$ Vid. MOLINA NAVARRETE, C.; et. alt.: Condiciones de trabajo y riesgos psicosociales relacionados con las adicciones: Prevalencias de consumo y acciones preventivas en el entorno laboral, óp. cit., pág. 77.

32 Disponible en http://www.pnsd.mscbs.gob.es/pnsd/estrategiaNacional/home.htm

${ }^{33}$ Información disponible en http://www.pnsd.mscbs.gob.es/pnsd/planAccion/home.htm
} 
las propias organizaciones empresariales ${ }^{34}$. A partir de lo anterior, entendemos que sería necesario que se incluyera expresamente este modelo de gestión "preventivopromocional" de los consumos problemáticos de drogas y otras adicciones en el sistema normativo de seguridad y salud en el trabajo.

Precisamente, a nuestro entender además es de vital importancia que el tratamiento preventivo de las adicciones se desarrollara mediante la negociación colectiva, donde se establecen algunas prácticas muy interesantes, si bien, aún podemos constatar que son muy pocos convenios colectivos los que tratan esta materia desde la perspectiva preventiva ${ }^{35}$. De hecho la negociación colectiva se ha visto marcada por el enfoque negativo del art. 54.2 f) Estatuto de los Trabajadores reflejándose en los convenios esa pauta represiva del tratamiento de las adicciones en los entornos de trabajo ${ }^{36}$, incluso ampliando el consumo ocasional y extralaboral, siempre y cuando tenga una incidencia negativa en la imagen de la empresa, por ejemplo mediante el trabajador que aporta un uniforme o distintivos de la empresa ${ }^{37}$.

Por otro lado, algo más extendidas son las acciones que prefieren firmar un "protocolo de gestión de las drogas y/o adicciones conductuales” a fin de fomenta esta forma de gestión más informal, previo mandato convencional.

En suma, a día de hoy, continua existiendo una contracción entre, de un lado, el marco regulador que mantiene inalterado la dimensión reactiva y disciplinaria, de otro, con el marco estratégico e institucional, que promueve una gestión integral y proactiva.

\section{HACIA UN NUEVO ENFOQUE: LA GESTIÓN PREVENTIVA INTEGRAL DE SEGURIDAD Y SALUD LABORAL}

Frente a esta dimensión sancionadora de las adicciones con o sin sustancia, como ya se ha determinado, lentamente se va abriendo otra vía muy diferente de actuación en las organizaciones empresariales. Este nuevo enfoque es coherente con los principios preventivos, donde la empresa y representación laboral deberán de potenciar la concienciación de los trabajadores acerca de las bondades de consumos inocuos, generando una concienciación e implicación en relación a la protección de la salud y bienestar.

Por todo ello, se deberá de desarrollar una política integral, completa e integrada de gestión del riesgo de las adicciones en los lugares de trabajo abarcando diferentes facetas de la acción integral como son la función preventiva (evaluación de riesgos laborales y vigilancia de la salud), asistencial (mejoras sociales), promocional

\footnotetext{
34 Vid. FERNANDEZ DOMÍNGUEZ, J.J.: "La embriaguez habitual como causa de despido y/o la asistencia al trabajador con problemas de alcohol y drogas”, Revista de trabajo y seguridad social: CEF, núm. 365-366, 2013, pág. 141.

35 Vid. MOLINA NAVARRETE, C., MIÑARRO YANINI, M., GARCÍA JIMÉNEZ, M., ESCARABAJAL ARRIETA, D. y PULIDO MARTOS, M.: Jóvenes, riesgo de adiciones y el tránsito del entorno educativo al trabajo: Qué saber (riesgo y daños) y cómo saber prevenir (protección y salud), Secretaría de Salud Laboral y Medio Ambiente UGT-CEC, 2019, pág. 26.

36 Vid. ÁLVAREZ MONTERO, A.: “Tratamiento convencional de los consumos problemáticos de drogas en los ambientes de trabajo: Entre tradición y renovación”, Revista de trabajo y seguridad social: CEF, núm. 398, 2016, pág. 130.

${ }^{37}$ Vid. MIÑARRO YANINI, M.: "El modelo regulador de las adicciones en los ambientes de trabajo en España: Contradicciones y propuestas de cambio”, óp. cit., pág. 117.
} 
(programas de fomento de hábitos de vida saludable) y, en último lugar, la función disciplinaria (régimen infractor).

$\mathrm{Y}$ es que, ciertamente, el proceso de gestión integral en los lugares de trabajo de las adicciones deberá de seguir un proceso o ciclo preventivo típico del sistema de seguridad y salud en el trabajo. Por tanto, en una primera fase habrá que evaluar los factores de riesgo, es decir, las condiciones de trabajo que generan la probabilidad de que se produzcan situaciones nocivas para el bienestar o salud de los trabajadores y asociados al ambiente de trabajo para, con posterioridad, identificar los factores de protección frente a los mismos.

Cabe destacar como pieza clave en aras a conseguir la mayor protección del trabajador, la actividad evaluadora de los riesgos laborales ${ }^{38}$, con independencia del tamaño de la empresa y del sector productivo, para conocer las condiciones de cada uno de los puestos de trabajo, es decir, del conjunto de la actividad productiva de la empresa $^{39}$, abarcando todos los aspectos del trabajo. En consecuencia, se establece como la primera y primordial acción preventiva que ha de desarrollar el empleador, pues de los resultados de ella estriba el cumplimiento de las demás obligaciones reguladas en el entramado normativo sobre la seguridad y salud laboral (STC 62/2007, de 27 de marzo y STC 160/2007, de 2 de julio) ${ }^{40}$.

Finalmente en este proceso o ciclo preventivo y a partir de la evaluación de los factores de riesgo se incorporará dentro del Plan de Riesgos Laborales el programa de gestión de las adicciones como riesgo de conformidad con el art. 16 LPRL.

A este respecto, existe una evidencia experimental de la conexión entre la evaluación de riesgos laborales y la política promocional de gestión de consumos problemáticos, como propone la OIT y su programa SOLVE, pues pone de manifiesto la mayor eficacia de ambas, existiendo una relación sinérgica o positiva. Esto es, la Segunda Encuesta Europea de Empresas sobre Riesgos Nuevos y Emergentes (ESENER-2) ${ }^{41}$, encuentra una relación positiva entre la herramienta básica sobre la que se construye todo el edificio preventivo de riesgos laborales, la evaluación de riesgos, y la acción promocional de la salud en relación a los consumos de riesgo respecto de drogas y demás adicciones. De manera que aquellas empresas que deciden implementar

\footnotetext{
${ }^{38}$ Vid. DE LA CASA QUESADA y GARCÍA JIMÉNEZ, M.: El plan de prevención de riesgos laborales en la empresa. Organización, evaluación y planificación, Editorial Comares, Granada, 2009, pág. 27.

${ }^{39}$ Vid. FERNÁNDEZ MARCOS, L.: "El ámbito natural de la evaluación de riesgos en la normativa preventiva”, en Aranzadi Social, núm. 5, 2000, pág. 635.

${ }^{40}$ Vid. VILLAR CAÑADA, I. y VALLECILLO GÁMEZ, M.R.: Reestructuraciones empresariales, riesgos psicosociales y bienestar en el trabajo. Una nueva dimensión del modelo comunitario de gestión social, Editorial Comares, Granada, 2011, pág. 52.

${ }^{41}$ La Encuesta europea de empresas sobre riesgos nuevos y emergentes (ESENER) elaborada por la Agencia Europea para la Seguridad y la Salud en el Trabajo desarrolla un importante estudio en toda Europa sobre la materia de seguridad y salud acerca de la manera en que se gestionan los riesgos laborales en el lugar de trabajo, teniendo especial interés sobre los riesgos psicosociales. En la actualidad contamos con tres encuestas ESENER-1, ESENER-2 y ESENER-3. En el año 2009 se elaboró la primera edición de ESENER, confeccionando una segunda edición en el año 2014 siendo más detallada y extensa que la primera. Si bien, en la actualidad se encuentran realizando un análisis de los datos obtenidos en el estudio de campo para la que es la tercera edición de ESENER, la cual se presentarán los primeros informes en el año 2021. En este sentido, véase IRASTORZA, X.; MILCZAREK, M. y COCKBURN, W.: Second European Survey of Enterprises on New and Emerging Risks (ESENER-2), Agencia Europea para la Seguridad y Salud en el Trabajo (EU-OSHA), Luxemburgo, 2016. Documento disponible en el siguiente enlace: https://osha.europa.eu/es/tools-and-publications/publications/second-european-surveyenterprises-new-and-emerging-risks-esener
} 
medidas para concienciar sobre la prevención de adicciones son principalmente aquellas que desarrollan una evaluación de riesgos (42,6\%), frente a las que no evalúan (26,7\%). Esta relación se encuentra en todos los países de la UE, de modo que la acción preventiva en general, y en riesgos psicosociales en particular, facilita la promoción de conductas saludables respecto de consumos problemáticos.

Esta política de prevención-promoción de la salud y bienestar laboral frente al riesgo de adicciones puede contar con dos instrumentos o herramientas de gestión básicos.

En primer lugar, con la vigilancia de la salud laboral (art. 22 LPRL) que constituye una actividad preventiva orientada a la protección más precoz posible de la salud de las personas, es decir, en el ámbito laboral, de los trabajadores, a partir de la identificación de los eventuales síntomas o patologías mediante exámenes o reconocimientos médicos. Ahora bien, además de exigir, con carácter general, el consentimiento de los trabajadores, se ha de tener presente que esta vía no pueda utilizarse para favorecer las acciones disciplinarias. De tal forma que las pruebas sólo pueden utilizarse, sin perjuicio de la necesaria confidencialidad sobre los datos médicos, para el fin de protección y promoción de la salud de los trabajadores ${ }^{42}$.

La segunda herramienta sería la elaboración e implementación de planes de acción o programas de protección, así como de los protocolos de intervención en materia de gestión de drogas y adicciones en el trabajo.

Por razones de eficacia, eficiencia, trasparencia y equidad, la intervención frente al problema de adicciones en cualquier ámbito, entre los que se cuenta de igual modo el en el entorno laboral, requiere de una adecuada planificación, en términos similares a lo que sucede con los demás riesgos laborales. Así, tanto la OMS como la OIT recomiendan garantizar, un "plan de acción integral” al respecto, normalizando y formalizando el tratamiento frente a los riesgos de consumos indebidos o problemáticos. De este modo, ese carácter integral coherente con la LPRL, se debería articular a través de la integración armonizada, de tres “programas de protección”, según el momento de intervención en los procesos de riesgo de drogodependencias.

- Programa de prevención: se pretende evitar o minimizar los factores de riesgo y potenciar los factores de protección, en relación a todos los agentes que inducen o provocan recaídas a las personas en riesgo de conductas adictivas.

- Programa de asistencia: con los que facilitar la detección e intervención precoz de los problemas, canalizando adecuadamente a las personas hacia la red de centros especializados.

- Programas de rehabilitación: que se orientan a disponer recursos, propios y ajenos, para facilitar la desintoxicación, deshabituación y, sobre todo, la reinserción de la persona dependiente a su medio, incluido el laboral.

Por lo que respecta a los Delegados de Prevención de Riesgos, por sí solos o en el marco de su actuación dentro del Comité de Seguridad y Salud en el Trabajo, tienen en sus manos la facultad de propuesta de protocolos de prevención de consumo de drogas en las organizaciones empresariales ${ }^{43}$.

\footnotetext{
42 Vid. MOLINA NAVARRETE, C.: "Vigilancia de la salud laboral, consentimiento <<desinformado >> y <<¿¿ímites al secreto médico?>>”, Revista de trabajo y seguridad social: CEF, núm. 404, 2016, pág. 8.

43 De hecho, la planificación e implementación de la prevención de riesgos laborales no es una actividad unilateral del empresario, sino que deberán de consultar y negociar de manera permanente con los trabajadores (art. 5 RSP). De tal forma que dentro del imperativo de integración de la prevención de los
} 
Ciertamente, esta labor, allí donde existan estas estructuras de representación y que será en las empresas de ciertas dimensiones (más de 50 trabajadores, para los Comités de Seguridad y Salud en el Trabajo), estará plagada de dificultades, sin duda. No obstante, el Delegado, consciente en todo momento de que los trabajadores tienen garantía de confidencialidad del tratamiento y de la prohibición de pruebas de detección de drogas sin consentimiento, salvo que esté en juego la seguridad de terceras personas otros compañeros, clientes, usuarios, etc.-, debe romper ese "círculo vicioso" del silencio y convertirse en la "voz" del colectivo, pasando a las "palabras" y de éstas a la "acción”. Con todo, como es sabido, para actualizar esa función innovadora y de mejora, la representación laboral tiene un amplísimo abanico de facultades, todas ellas con específica previsión legislativa.

En síntesis, el Delegado puede desarrollar las siguientes acciones ${ }^{44}$ :

- Mantener y persistir en la consideración de la drogodependencia desde la perspectiva de la salud para su tratamiento como enfermedad tanto en la negociación de planes y medidas, como en las conductas individuales que puedan manifestarse.

- Participar en la creación, desarrollo, seguimiento y evaluación del Plan.

- El asesoramiento y orientación manteniendo el respeto, la tolerancia y la confidencialidad de todos los trabajadores.

- Asunción del rol de mediadores y garantes de derechos laborales y sociales de los trabajadores principalmente de su salud y de su estabilidad en el empleo.

- Proporcionar apoyo y orientación en todas las fases de desarrollo del plan de acción.

- Vigilar que todas las pruebas y diagnósticos de salud estén orientados a prevenir y superar las situaciones de drogodependencia y adicciones.

- Garantizar la voluntariedad y confidencialidad de los exámenes de salud.

- Garantizar que el plan prevea la incapacidad temporal como única alternativa de suspensión de la relación durante el tratamiento y, en su caso, la adaptación de la jornada y flexibilidad horaria con este fin.

- Negociar que lo fondos de acción social de la empresa contenga partidas para la financiación del tratamiento si los servicios no fueran públicos y gratuitos.

- Negociar y prever la movilidad funcional en puestos de trabajo susceptibles de facilitar el consumo así como la reincorporación posterior al tratamiento, si fuera conveniente para facilitar la consolidación de la abstinencia del trabajador.

En vista a todo lo anterior, consideramos interesante el análisis de algunas experiencias que generan un valor añadido a este trabajo de investigación. Si es cierto que no pretendemos un análisis pormenorizado de esta dimensión, muy relevante y que exige profundización. No obstante, sí es oportuno ofrecer algunos balances sobre la eficacia de algunas experiencias que han decidido afrontar ese proceso de integración, más o menos coherente e integral, de la promoción de la salud en el trabajo en sus

riesgos labores se encuentra la implicación a los trabajadores y sus diversas estructuras de representación, como principio de prevención participada (arts.33 a 36 LPRL).

44 Vid. MOLINA NAVARRETE, C., et. alt.: "Drogodependencias y adicciones en los ambientes de trabajo: Buenas prácticas de regulación y gestión negociadas”, óp. cit., pág. 74. 
políticas de seguridad y salud en el trabajo, con especial referencia a la gestión de los consumos problemáticos de drogas.

Precisamente, siguiendo una línea de convicción análoga, y a partir del III Acuerdo de Empleo y Negociación Colectiva que se comprometía a establecer instrumentos para, en el marco de la prevención de accidentes de trabajo, identificar y buscar solución a las situaciones y riesgos derivados de la problemática por el consumo de alcohol, drogas y otras sustancias ${ }^{45}$, en esa dirección de compromiso convencional ya hay algunas prácticas muy interesantes, tanto como escasas. A título de ejemplo sería el art. 55 del Convenio colectivo estatal de acción e intervención social ${ }^{46}$. En dicho precepto tras razonar la dimensión de riesgo psicosocial complejo de los consumos nocivos, se aportan argumentos para promover un plan de gestión integral. De manera que en este convenio se establece que el consumo de drogas implica problemas de salud con repercusiones individuales y colectivas, donde el inicio o incremento del consumo de drogas en el ámbito laboral puede ser ocasionado por condiciones de paro, precariedad o malas condiciones de trabajo.

A ello hay que añadir que este tipo de cláusulas convencionales establecen diferentes mandatos y atribuciones de competencia, a fin de dotarlos de contenido con posterioridad en el ámbito de cada entidad junto con la representación legal de los trabajadores si la hubiera. En este sentido, se dispone diferentes principios o ámbitos de acción, como son en materia:

- Preventiva. Se priorizarán medidas educativas, informativas y formativas que motiven la reducción y el uso inadecuado de drogas y promocionen hábitos saludables. Asimismo se potenciará la modificación de factores de riesgo y la mejora de las condiciones de trabajo.

- Asistencial. Se facilitará el acceso a los programas de tratamiento de las entidades del sector a aquel personal que lo solicite.

- Reinsertiva. El objetivo fundamental de toda acción es devolver la salud al sujeto y facilitar la reincorporación del personal a su puesto de trabajo.

- Participativa. Toda iniciativa o programa empresarial de carácter colectivo relacionados con las drogodependencias será consultada, con carácter previo, a la representación legal...

- No sancionadora. El personal que se acoja a un programa de tratamiento no podrá ser objeto de sanción o despido por esta causa o por las acciones derivadas de la misma y se le asegurará su reincorporación inmediata a su puesto de trabajo si es necesario.

Otras experiencias, algo más extendidas, prefieren firmar un protocolo de gestión de las drogas y/o adicciones, a fin de fomenta esta forma de gestión más asistencial y evitando el tradicional enfoque disciplinario hacia el enfoque más preventivo promovida por la Estrategia Nacional de Adicciones 2017-2024. En esta línea, es de interés el art. 30 del convenio colectivo de la empresa Opel España, S.L.U. ${ }^{47}$ que establece un programa de "lucha contra el alcohol, las drogas y la ludopatía". Las razones dadas por los negociadores del convenio para asumir esta política de gestión del riesgo de adicciones en el trabajo coiciden con las dadas por la OIT. Asimismo, se

\footnotetext{
${ }^{45}$ Ahora bien, aunque el IV Acuerdo de Empleo y Negociación Colectiva no lo recoge expresamente, sí se entiende vigente por la remisión que a estos otros aspectos hace.

${ }^{46}$ BOE, núm. 158, de 3 de julio de 2015.

${ }^{47}$ BOP Zaragoza, núm. 61, de 16 de marzo de 2018.
} 
acuerda el principio de participacion del Comité de Empresa y sindicatos y su cooperacion con el Departamento de Prevencion y Comité de Seguridady Salud en el trabajo, siendo un aspecto primordial para una prevencion eficaz en esta materia. No obstante, consideramos que pese al enfoque preventivo que se le quiere aportar a este Programa, si bien, se centra fundamentalmente en la faceta asistencial.

En línea análoga, con la incorporación de procedimientos de gestión de drogas y otras adicciones en el convenio colectivo nos encontramos con la Empresa de ACOSOL, S.A. En su art. 63 relativo a la metria de seguridad y salud en el trabajo de su convenio colectivo remite expresamente al protocolo que se firmó con los sindicatos más representativos, esto es, "en cuanto a la prevención e intervención de drogodependencia, alcoholismo y ludopatía, se estará a lo acordado en el Protocolo firmado".

En definitiva, vemos cómo hay un importante marco institucional favorable a la gestión preventiva de los factores de riesgo de adicciones asociados al trabajo, así como de fomento de los factores de protección frente a ellos ligados al trabajo. Comprobamos que hay algunas experiencias también en esa línea y que todos están convencidos de las bondades sociales y económicas de esa gestión integrada, promocionada por la OIT. Pero, pese a todo, la progresión de estas prácticas, de esta experiencia, sigue estancada y son una minoría. En cambio, por sus beneficios, debería ser una práctica más habitual y a identificar los factores que ayudarían a que así fuese se dirige este Proyecto de Investigación.

En suma, es de destacar que la necesidad y razones para actuar pocas dudas puede haber. Precisamente, por esta necesidad en la actualidad es manifiesto que el enfoque represivo-disciplinario resulta mucho más ineficiente que el preventivo, por cuanto que el ejercicio del poder sancionador no evitará el que la empresa tenga que afrontar elevadísimos costes, sean directos sean indirectos. Consecuentemente, el enfoque preventivo, según ilustra la OIT, no sólo resulta más justo, sino más eficiente desde la prevalente óptica económica actual, por cuanto ahorra costes importantes no sólo al sistema de servicios socio-sanitarios públicos y al sistema productivo en general, sino también, y lo que resulta más tangible, a la empresa, mejorando netamente además, según confirman las experiencias aquí analizadas, la productividad ${ }^{48}$.

Sin embargo, el problema principal es cómo hacerlo y así lo prueba el que las iniciativas preventivas en nuestra experiencia de relaciones laborales son muy reducidas, no inexistentes, si bien, crecientes, pero, en todo caso, poco significativa en el plano cuantitativo, pues tan sólo afecta a un reducido número de empresas y convenios colectivos. Ahora bien, aunque no existe tampoco un modelo único de acción, sí se pueden desarrollar políticas concretas, de manera que mientras unos se alinean con un enfoque amplio e integral de las políticas de seguridad y salud en el trabajo, en los términos de sistema normativo, institucional y técnico de la LPRL, por lo tanto, incluida tanto la evaluación como la planificación preventiva; otros prefieren implementar el modelo más voluntarista y ético-social, de la promoción de la salud de los trabajadores según el enfoque de la responsabilidad social y las empresas saludables,

\footnotetext{
${ }^{48}$ Vid. RIBAS, E.; PORTELLA, E.; RIDAO, M.; CARRILO, E. y CAMACHO, C: "Los costes derivados del consumo de alcohol para el sistema productivo en España”, Adicciones, Vol. 11, n. 1, 1999, págs.3336. En el mismo sentido, véase FORTUNY, R.: "Evaluación de resultados y rentabilidad”, Mapfre Medicina, vol. 4, n.3, 1993, págs.34-38. Igualmente puede decirse de los numerosos estudios incluidos en el Cuaderno de Formación del PROGRAMA SOLVE, de la OIT.
} 
que enfatizan un enfoque individualista ${ }^{49}$, esto es, la mejora de los estilos de vida y hábitos saludables.

Con todo, se trata de una cuestión social que, en consecuencia, exige un adecuado reparto de responsabilidades, sin que pueda quedarse relegado en la esfera personal y familiar ni pueda externalizarse sólo en políticas y servicios de naturaleza pública, cuando los factores organizativos y socio-laborales resultarán claves en las interacciones que llevan a, o hacen más probable los, consumos y las adicciones.

\section{PROPUESTAS DE MEJORA Y CONCLUSIONES}

Una vez realizado el análisis en las páginas anteriores ha quedado expuesto la paridad de perspectivas y tratamientos en relación a las adicciones en el ámbito del trabajo siendo poco coherente nuestro sistema. En la actualidad, la legislación laboral se resiste al cambio constatándose una profunda y grave contradicción, partiendo de la base de que el consumo problemático y las conductas adictivas son "enfermedades voluntarias", siendo una afirmación inadecuada, puesto que la existencia de una adicción excluye voluntariedad de la persona al depender de la sustancia o conducta adictiva y, por tanto, ésta domina a aquélla. En consecuencia, desde el punto de vista práctico este enfoque se ha traducido a acciones que relegan a un plano voluntario por parte de las empresas para su prevención y tratamiento en el ámbito del trabajo, primando un cariz represivo-sancionador a través del despido.

En este sentido, hemos estudiado la dificultad para impulsar los cambios necesarios desde el punto de vista de la prevención de los riesgos laborales. Sin embargo, existen evidencias institucionalizadas que han buscado soluciones aptas para la salud y bienestar de las personas y también para las empresas, y de la sociedad en su conjunto. Igualmente, a pesar de que no es fácil que la negociación colectiva prescinda de la inercia represiva o sancionadora del enfoque normativo existen algunas experiencias también en esa línea, donde cada vez más las organizaciones empresariales están convencidos de las bondades sociales y económicas de esa gestión integrada, promocionada por la OIT. No obstante, pese a todo, la progresión de estas prácticas y de esta experiencia, aún sigue estancada y son una minoría. En cambio, por sus beneficios, debería ser una práctica más habitual, donde se identifiquen los factores y elementos que ayudarían a que así fuese.

En cualquier caso, entendemos necesario determinar un conjunto de propuestas de mejoras en actuación que urgen para que el actual panorama cambie. De manera que, desde la perspectiva de prevención de riesgos laborales que aquí nos interesa, algunas propuestas son:

1. Suprimir el art. 54.2.f) ET. Urge la derogación de dicho precepto dado que mantiene el carácter represivo, sancionador, siendo contraproducente a efectos de rehabilitación y reinserción de estas enfermedades dentro del ordenamiento jurídico. Como precisábamos, es esencial su supresión por su carácter disfuncional e innecesario, careciendo de utilidad, puesto que

\footnotetext{
${ }^{49}$ Un ejemplo de ello nos lo encontramos a través de las SAN 55/2017, de 21 de abril de 2017. En este sentido, a petición de algunos trabajadores se implantó un plan en la empresa denominado "Sabemos cuidarnos", dividido en bloques y completado por un catálogo de actividades, dirigido a mejorar la salud de los trabajadores mediante el fomento de hábitos saludables. La empresa, a fin de incentivar su realización efectiva, vinculó al cumplimiento del programa una parte de la retribución variable, si bien, la gestión unilateral y novatoria del mismo llevó a la impugnación sindical de las decisiones del empleador.
} 
existen otros preceptos sancionadores más garantistas con idéntico resultado.

2. Especificar en el marco legal la dimensión preventiva ante las adicciones con carácter general, en los ambientes laborales. Ello supone la superación del paradigma actual disciplinario, evolucionando hacia una óptica preventiva y de tratamiento de las adicciones e integrándose en la prevención de riesgos laborales (art. 14 LPRL), aportando un marco homogéneo y claro. Así, dichos consumos problemáticos y adictivos pasan a conformarse como riesgos psicosociales, siendo objeto de la evaluación de riesgos laborales y de las acciones preventivas que procedan. De hecho, es necesario visualizarlo como enfermedad mental que requiere de acciones proactivas para evitarla, es decir, para prevenirla o, en su caso, protectoras, para corregir sus efectos y normalizar, médica, social y laboralmente a la persona afectada por el problema de salud.

3. Promover el tratamiento de las adicciones en la negociación colectiva acorde con el sistema de seguridad y salud en el trabajo. Resulta de gran interés que, dada la complejidad del fenómeno, se aporten unas pautas o criterios para una gestión integral de conductas de riesgo adictivo. Al respecto, la negociación colectiva tiene reconocida la facultad de mejorar y desarrollar las disposiciones de carácter laboral, de manera que las acciones que pueden desarrollar los representantes de los trabajadores sobre esta materia son fundamentales. Así, la autonomía colectiva es una herramienta extraordinaria que, en el ámbito de las adicciones, se convierte más que un instrumento de mejora de la protección, es una herramienta que garantiza una eficaz aplicación de una política preventiva en la organización empresarial. De hecho se caracteriza por su adaptación a las necesidades reales en materia preventiva del sector o empresa, debido a que los implicados en su negociación son los mayores conocedores de los posibles riesgos presentes en el entorno de trabajo.

Finalmente, como conclusión a este estudio, se ha mostrado un conjunto de evidencias estadísticas relevantes que han manifestado la necesidad de un cambio de perspectiva, puesto que se ha podido comprobar que, de un lado, existen ciertos perfiles sociodemográficos más expuestos al consumo de determinados tipos de sustancias. Así, hay ciertos elementos del contexto laboral y de las condiciones de trabajo (sector, ocupación, jornada, factores de riesgo, entre otros) que aumentan la prevalencia de cierto tipo de consumos y adicciones. De esto se deriva que la combinación de determinados factores individuales, organizativos y socio-laborales expone a un mayor riesgo de consumos problemáticos a una parte de la población laboral, eliminando la visión acerca de que las adicciones es una cuestión extralaboral.

Sin duda, a pesar de la lenta pero si gradual experiencia, hemos podido comprobar cómo se ha establecido un importante marco favorable a la gestión preventiva de los factores de riesgo de adicciones asociados al trabajo, así como de fomento de los factores de protección frente a ellos ligados al trabajo. De hecho los datos disponibles a partir de la Encuesta ESENER-2 muestran con claridad que existe una relación positiva entre los programas de promoción de la salud que contemplan gestión de consumos problemáticos y las evaluaciones de riesgos psicosociales (art. 15 LPRL) dada la interrelación existente entre todos ellos, en especial entre los sociodemográficos y los laborales. Por lo tanto, la evidencia experimental coincide con la 
científico-analítica a la hora de primar el enfoque objetivo-organizativo sobre el individual-asistencial.

Por lo que respecta a la complejidad de la acción preventiva no debe de disuadir de integrar este enfoque en la gestión integral de seguridad y salud en el trabajo en las empresas, por la consideración de una pretendida dificultad extrema y altos costes, en particular para empresas de menor tamaño, incluso empresas medianas. Al contrario, a día de hoy, disponemos, ya con una acreditada solvencia, científica y experimental, en el seno de la OIT, de herramientas de gestión que garantizan que la prevención no sólo es adaptable a cada tipo de organización empresarial, sino que es sostenible financieramente a lo largo del tiempo.

En suma, desde la perspectiva de política completa de gestión del riesgo de las adicciones en los lugares de trabajo que aquí nos interesa, las conductas excesivas y repetitivas constituyen una relevante cuestión de salud y de equidad social, tanto si se trata de un problema de conductas compulsivas, incluso de hábitos no saludables repetitivos. Si bien, en la actualidad sigue siendo un reto anclado en el pasado, no obstante, ha de ser renovado a través del tratamiento desde diferentes perspectivas y facetas con el objeto de hallar una solución más beneficiosa social y económicamente, adecuándose a la sociedad actual y a las nuevas necesidades, dejando como última vía la función disciplinaria, siendo el primordial aspecto que en este trabajo de investigación nos ha interesado y que se distingue prioritariamente.

\section{BIBLIOGRAFÍA}

AA.VV. Encuesta 2013-2014 sobre consumo de sustancias psicoactivas en el ámbito laboral en España, Ministerio de Sanidad, Servicios Sociales e Igualdad, 2015. Disponible

en http://www.pnsd.mscbs.gob.es/noticiasEventos/dossier/pdf/EncuestaLaboral201 3.pdf

AA.VV. Encuesta sobre alcohol y otras drogas en España (EDADES). 1995-2017. Disponible en http://www.pnsd.mscbs.gob.es/profesionales/sistemasInformacion/sistemaInfor macion/pdf/EDADES_2017_Informe.pdf

AA.VV. Estrategia Nacional sobre Adicciones. 2017-2024. Ministerio de Sanidad, Servicios Sociales e Igualdad, 2017. Disponible en http://www.pnsd.mscbs.gob.es/pnsd/estrategiaNacional/docs/180209_ESTRATE GIA_N.ADICCIONES_2017-2024_aprobada_CM.pdf

AA.VV. Informe sobre Adicciones comportamentales. Juego y uso compulsivo de internet en las encuestas de drogas y adicciones en España EDADES y ESTUDES. Disponible en http://www.pnsd.mscbs.gob.es/profesionales/sistemasInformacion/sistemaInfor macion/pdf/2019_Informe_adicciones_comportamentales.pdf

AA.VV. SOLVE: Integrando la promoción de la salud a las políticas de SST en el lugar de trabajo, OIT, 2012.

ÁLVAREZ MONTERO, A.: "Tratamiento convencional de los consumos problemáticos de drogas en los ambientes de trabajo: Entre tradición y renovación”, Revista de trabajo y seguridad social: CEF, núm. 398, 2016, págs. 113-136.

DE LA CASA QUESADA y GARCÍA JIMÉNEZ, M.: El plan de prevención de riesgos laborales en la empresa. Organización, evaluación y planificación, Editorial Comares, Granada, 2009. 
FERNANDEZ DOMÍNGUEZ, J.J.: "La embriaguez habitual como causa de despido y/o la asistencia al trabajador con problemas de alcohol y drogas", Revista de trabajo y seguridad social: CEF, núm. 365-366, 2013, págs. 135-162.

FERNÁNDEZ MARCOS, L.: "El ámbito natural de la evaluación de riesgos en la normativa preventiva”, en Aranzadi Social, núm. 5, 2000, págs. 631-646.

FORTUNY, R.: "Evaluación de resultados y rentabilidad”, Mapfre Medicina, vol. 4, n.3, 1993, págs.34-38.

GARCÍA NINET, J.I., y VICENTE PALACIO, A.: “Artículo 25. Protección de trabajadores especialmente sensibles a determinados riesgos”, en AA.VV. MONEREO PÉREZ, J.L., MOLINA NAVARRETE, C. y MORENO VIDA, M.N. (dirs.) Comentario a la Ley de Prevención de Riesgos Laborales y sus desarrollos reglamentarios, Comares, Granada, 2004, págs. 250-258.

GARCÍA-PERROTE ESCARTÍN, I.: "Protección de trabajadores especialmente sensibles a determinados riesgos”, en AA.VV. CASAS BAAMONDE M.E., PALOMEQUE LÓPEZ M.C., VALDÉS DAL-RE, F (coord.), Seguridad y Salud en el Trabajo. El nuevo derecho de prevención de riesgos profesionales. La Ley-Actualidad, Madrid, 1997.

GARRIDO FALLA, F.: “Artículo 43”, en AA.VV. GARRIDO FALLA, F. (coord.): Comentarios a la Constitución, Civitas, Madrid, 1985.

GARRIGUES GIMÉNEZ, A.: "La prevención de riesgos laborales en el marco de la Constitución Europea”, en Revista del Ministerio de Trabajo y Asuntos Sociales, núm.57, 2005, págs. 353366.

GÓMEZ SALADO, M.A.: “El absentismo laboral como causa del despido objetivo. Puntos críticos en la redacción del artículo 52 d) del Estatuto de los Trabajadores”, Editorial Comares, Granada, 2019.

GONZÁLEZ ORTEGA, S.: "Derecho a la salud y control de los trabajadores", en Relaciones laborales: Revista crítica de teoría y práctica, núm. 1, 1990, págs. 240-254.

GONZÁLEZ-POSADAS MARTÍNEZ, E.: "La seguridad y salud de los trabajadores", en AA.VV. SEMPERRE NAVARRO, A.V. (Dir.) El modelo social en la Constitución Española de 1978, Ministerio de Trabajo y Asuntos Sociales, Madrid, 2003, pág. 759-783.

IRASTORZA, X.; MILCZAREK, M. y COCKBURN, W.: Second European Survey of Enterprises on New and Emerging Risks (ESENER-2), Agencia Europea para la Seguridad y Salud en el Trabajo (EU-OSHA), Luxemburgo, 2016.

MIÑARRO YANINI, M.: "El modelo regulador de las adicciones en los ambientes de trabajo en España: Contradicciones y propuestas de cambio”, en Temas Laborales, núm. 134, 2016.

MOLINA NAVARRETE, C. y VALLECILLO GÁMEZ, M.R.: Adicciones conductuales ("sin sustancia") "en" el trabajo y "al” trabajo: Magnitud del problema social y políticas de gestión preventiva en la empresa, Secretaría de Salud Laboral y Medio Ambiente UGT-CEC, 2018.

MOLINA NAVARRETE, C., MIÑARRO YANINI, M., ÁLVAREZ MONTERO, A., GARCÍA CÍVICO, J. y GONZÁLEZ COBALEDA, E. "Drogodependencias y adicciones en los ambientes de trabajo: Buenas prácticas de regulación y gestión negociadas”, Secretaría de Salud Laboral y Medio Ambiente UGT-CEC, 2016.

MOLINA NAVARRETE, C., MIÑARRO YANINI, M., GARCÍA JIMÉNEZ, M., ESCARABAJAL ARRIETA, D. y PULIDO MARTOS, M.: Jóvenes, riesgo de adiciones y el tránsito del entorno educativo al trabajo: Qué saber (riesgo y daños) y cómo saber prevenir (protección y salud), Secretaría de Salud Laboral y Medio Ambiente UGT-CEC, 2019.

MOLINA NAVARRETE, C.: "La tutela frente a la <<violencia moral >> en los lugares de trabajo: entre prevención e indemnización”, Aranzadi Social, núm. 8, 2002, págs. 1127-1172.

MOLINA NAVARRETE, C.: Vigilancia de la salud laboral, consentimiento $<<$ desinformado $>>$ y <<¿límites al secreto médico?>>, Revista de trabajo y seguridad social: CEF, núm. 404, 2016, págs. 5-12. 
MOLINA NAVARRETE, C.; MIÑARRO YANINI, M., GARCÍA JIMÉNEZ, M. y GIL DOMINGUEZ, R.: La prevención del riesgo de adicciones en el medio laboral: obligaciones, recomendaciones y buenas prácticas. Claves para una Nota Técnica Preventiva del INSBT, Secretaría de Salud Laboral y Medio Ambiente UGT-CEC, 2018.

MOLINA NAVARRETE, C.; MIÑARRO YANINI, M.; ESCARABAJAR ARRIETS, M.D.; GIMENO NAVARRO, M.A. y GONZÁLEZ COBALEDA, E.: Condiciones de trabajo y riesgos psicosociales relacionados con las adicciones: Prevalencias de consumo y acciones preventivas en el entorno laboral, Secretaría de Salud Laboral y Medio Ambiente UGT-CEC, 2016.

MONEREO PÉREZ, J.L. y MOLINA NAVARRETE, C.: “Capítulo 1: La caracterización general de la prevención de los riesgos laborales: Conceptos y fundamentos jurídicos-críticos del nuevo modelo de acción preventiva”, en AA.VV. MONEREO PÉREZ, J.L. y MOLINA NAVARRETE, C. (dir.): Tratado de Prevención de Riesgos Laborales. Teoría y Práctica, Tecnos, Madrid, 2015, págs. 15-66.

PALOMEQUE LÓPEZ, M.C.: "El derecho constitucional del trabajador a la seguridad en el trabajo”, en Actualidad Laboral, II, 1992, págs. 37-44.

PALOMEQUE LÓPEZ, M.C.: "La protección del trabajador frente a los riesgos laborales", en DS: Derecho y salud, Vol. 4, núm. 1, 1996, págs. 27-42.

RIBAS, E.; PORTELLA, E.; RIDAO, M.; CARRILO, E. y CAMACHO, C: "Los costes derivados del consumo de alcohol para el sistema productivo en España”, Adicciones, Vol. 11, n. 1, 1999, págs.33-36.

RIVERO LAMAS, J. Y DE VAL TENA, A. L.: “Artículo 15. Principios de la acción preventiva”, en AA.VV. MONEREO PÉREZ, J.L.; MOLINA NAVARRETE, C. y MORENO VIDA, M.N. (drs.): Comentario a la Ley de Prevención de Riesgos Laborales y sus desarrollos Reglamentarios, Comares, Granada, 2004, págs.133-140.

RODRÍGUEZ-PIÑERO Y BRAVO-FERRER, M.: "La integración de los derechos fundamentales en el contrato de trabajo”, en AA.VV. MARTÍN JIMÉNEZ, R. y SEMPERE NAVARRO, A.V. (coord.) El modelo social en la Constitución española de 1978, 2003, págs. 207-228.

VILLAR CAÑADA, I. y VALLECILLO GÁMEZ, M.R.: Reestructuraciones empresariales, riesgos psicosociales y bienestar en el trabajo. Una nueva dimensión del modelo comunitario de gestión social, Editorial Comares, Granada, 2011. 